\title{
Market Fragmentation, Market Quality and Clientele Effects
}

\author{
D. Alasdair S. Turnbull ${ }^{1}$ \\ ${ }^{1}$ David D. Reh School of Business, Clarkson University, Potsdam, New York, United States \\ Correspondence: D. Alasdair S. Turnbull, David D. Reh School of Business, Clarkson University, Potsdam, New \\ York, United States.
}

Received: November 13, 2017

Accepted: November 29, 2017

Online Published: Decemebr 3, 2017

doi:10.5430/ijfr.v9n1p74

URL: https://doi.org/10.5430/ijfr.v9n1p74

\begin{abstract}
This paper analyzes the relative trading activity of securities cross-listed on two highly integrated international stock exchanges. We find that traders choose an exchange on the basis of superior market quality, as measured by better quoted prices, greater depth at the market in its limit order book and better price continuity. As well, clientele effects influence trade location. From the perspective of a US investor, the price impacts of the total sample of trades for these securities, are statistically significantly lower on the New York Stock Exchange than on the Toronto Stock Exchange; but are not economically different. The results are consistent with the order splitting hypothesis and the co-existence of multiple markets.
\end{abstract}

Keywords: trade execution costs, cross-listed stocks, competition for order flow

\section{J.E.L. Classification Codes: G15, G24}

\section{Introduction}

The purpose of this paper is to examine theoretical models of market fragmentation through the analysis of securities cross-listed on two highly integrated international markets. In particular, we address the question of whether investors choose to trade in the market with the higher market quality as measured by better quoted prices, greater depth at the market in its limit order book and better price continuity, or whether there are other factors that influence their choice of trading venue. The answer to this question is relevant to the issue of how security exchanges compete with each other for trading volume and whether trading will inevitably gravitate to a single global exchange. The results have significant policy implications for the management of exchanges.

The paper examines trading activity and costs of securities cross-listed on the New York Stock Exchange (NYSE) and the Toronto Stock Exchange (TSE). (Note 1) The high integration of these markets is shown by the fact that arbitrage opportunities are relatively small, infrequent and short-lived.

A number of theoretical models of cross-listed securities are relevant to this study. The predictions of these models depend on the restrictions imposed on traders. The model of Pagano (1989) assumes that traders are free to choose where to trade and predicts that traders will migrate to the exchange with the lowest trading costs. The exchange with the lowest trading costs will attract additional trading volume, which in turn, will enhance liquidity and further lower trading costs. This feedback loop continues until all trading occurs on a single exchange.

In contrast, other papers provide reasons why trading will not gravitate to a single exchange. Chowdhry and Nanda (1991), assume that at least some liquidity traders have a special preference to trade in only one of the markets in which a security is cross-listed. Under this assumption, multiple markets with cross-listed securities are expected to coexist in equilibrium. The "winner takes most" feature of this model implies that trading will concentrate in the market that has the largest number of traders with the least discretion to move between markets. Thus, Chowdhry and Nanda (1991) indicate that multiple markets will coexist where there are exogenous factors, referred to as clientele effects, that lead some traders to select a particular trading venue over another.

As an example of clientele effects, some investors may prefer to trade in their home market for reasons of convenience and familiarity rather than choosing a foreign market which offers superior market quality. In particular, they may deal with a brokerage firm that is only a member of a domestic exchange. To trade on a foreign exchange would mean using a different broker. In addition, investors may have to transact in a foreign currency in order to buy 
or sell stock on a foreign stock exchange. Finally, if commissions are higher when dealing with a foreign stock exchange then this could also encourage trading in the domestic stock exchange. (Note 2)

Bernhardt and Hughson (1997) and Biais, Martimort and Rochet (2000) discuss how multiple markets allow traders to minimize the price impact of an order by splitting it into smaller orders and submitting them to two or more markets simultaneously. Thus, order splitting exploits, and in turn, reinforces the existence of multiple markets. The order splitting models suggest traders submit orders so that the marginal price impact from the last share in the orders submitted to each exchange should be equal. The exchange with the lowest transaction costs should receive the largest order. (Note 3) If multiple markets are to coexist, two testable implications are: on average, the transaction costs on the exchanges are equal and trading activity will be concentrated on the venue with the highest market quality.

To test these hypotheses, we need to measure both realized and potential transaction costs. Potential transaction costs are estimates of what it would have cost to put the trade through the alternate exchange. As potential transactions costs are a function of market spreads, the more efficient market will display narrower spreads. The more liquid market will display greater depth on the limit order book. However, liquidity is a function of total order flow. A commonly used measure of being able to trade in desired quantities without significantly moving the market is price continuity (trade price within one US cent of the previous trade price). These three market characteristics (best quoted price, volume at best quoted price and continuity of prices) are measures of what we refer to as market quality, that is how low potential transaction costs are on a given exchange.

The following specific questions about trading of cross-listed securities are addressed in this paper. How highly integrated are the NYSE and TSE; do arbitrage opportunities exist and for how long? To what extent are trades executed on the exchange with better market quality? Are clientele effects significant in choosing between the two trading venues? Are exchange rate adjusted order execution costs equal for cross-listed securities trading on the NYSE and the TSE?

The next section of the paper discusses institutional similarities and differences between the NYSE and the TSE that may affect trading costs. Section II of the paper discusses research methods and results. Conclusions are presented in the final section.

\section{Institutional Similarities and Differences between the TSE and NYSE}

In computing trade execution costs across two markets, we need to be cognizant of similarities and differences in their operations and regulatory structure. We refer to these differences as network externalities. Both the New York and the Toronto stock exchanges operate during identical trading hours in the same time zone, open as call markets, function as continuous auction markets after the open and have a penny tick size. (Note 4) In their downstairs markets, both exchanges rely on specialists who are responsible for making an orderly market for a number of stocks. There is, however, a significant difference in how orders are displayed. In Toronto, all orders are fully disclosed in the limit book whereas in New York, the specialist may (and often does) withhold a portion of the order from the market for a time. In New York, the specialist is the only market participant that always knows the true depth of the market. In addition, as discussed in Ready (1999), unlike the TSE, the specialist on the NYSE can "stop" a market order, which means he guarantees execution at the current quote but provides the possibility of price improvement

In the upstairs market of each exchange, client orders are often matched and sent to the exchange as crosses. However, on the TSE, the market makers can put crosses through the order book at a price that is at or between the best bid and ask quotes on the limit order book. Thus, the crosses on the TSE observe price but not time priority rules. In contrast, as described in Hasbrouck, Sofianos and Sosebee (1993), the rules on the NYSE for crossing orders are generally more restrictive than those on the TSE. NYSE Rule 76 requires that brokers, before proceeding with a cross, must make a bid on behalf of both sides of the cross, offering at a price one tick higher than their bid. The broker's orders are subject to the market's order-priority, order-exposure and price-improvement principles. This leads to orders sometimes being broken up as existing limit orders and floor brokers take precedence over the orders entered on behalf of both sides of the cross. No such rules apply on the TSE.

There are special rules on the NYSE that allow for block orders to be crossed outside the prevailing quote. When a member of the NYSE receives a block order that cannot be absorbed by the market, NYSE Rule 127 requires the member to explore crowd interest. The member wanting to cross a block of stock at a specific price outside the quotes must announce a clean-up price to the crowd and then fill all limit orders in the book up to that price, in the crowd and all better-displayed Intermarket Trading System (ITS) quotes as well as the "reasonable needs" of the specialist at that price. In contrast, on the TSE, when the price of the cross is outside the prevailing quotes, the 
upstairs trader must fill better-priced orders on the book, but does so at the standing price of the limit orders. From the viewpoint of the member institution and client trying to expedite an aggressive order through a cross, the NYSE rules are more costly than the TSE's.

In summary, the NYSE upstairs trading rules impose greater costs on upstairs trades and lead to more broken-up upstairs orders being filled in the downstairs market than in the TSE. (Note 5) This is consistent with the finding in Smith, Turnbull and White (2001) that crosses are much less frequent on the NYSE than the TSE. As well, on the TSE, the permanent price impact of upstairs trades is significantly lower than that of downstairs trades as information laden orders are screened out and sent to the downstairs market. There is also evidence of price improvement over market quotes in the upstairs market of the TSE. Thus, we expect operational efficiency is achieved mainly in the upstairs market of the TSE and the downstairs market of the NYSE.

Unlike almost all stocks from other countries, Canadian stocks are listed on the NYSE as ordinary shares rather than as American Depository Receipts (ADRs). Likewise, US stocks are listed on the TSE as ordinary shares. Canadian stocks listed as ordinary shares do not involve the conversion fees of switching from an ADR to the underlying home security. Furthermore, there are no legal restrictions on the cross-border ownership and trading of the Canadian stock listed on the NYSE and US stocks listed on the TSE. (Note 6)

Further driving greater integration between the two markets is the fact that arbitrage is relatively costless and riskless between the two exchanges. The large Canadian investment dealers employ traders who look for arbitrage opportunities between the two exchanges. (Note 7) It is expected that such traders will arbitrage orders submitted by small traders who are restricted to one exchange or who face significant cost differences in submitting orders across exchanges. To the extent that the clientele effect results in the price of a submitted buy order on one market being higher than the price of a submitted sell order on the other market by at least the all-in transaction costs of at least one market participant, there is a potential for arbitrage. Foreign exchange risk is not expected to be a significant factor as the exchange rate between the two countries' currencies is relatively stable.

\section{Analysis of Trading of Cross-listed Securities}

The paper conducts a series of tests to identify differences in trading activity and trade execution costs between the two exchanges and then examines the extent to which the differences arise because of market externalities, market quality and clientele effects. This study uses intraday quotes, trade prices and times gathered for both the TSE and the NYSE for all trading days over the period February 1, 2001 through April 20, 2001. The primary sources of data are: (Note 8)

1. The NYSE's TAQ Data Files,

2. TSE Equity history files, and

3. Intraday bid and ask quotes on C\$/US\$ exchange rates provided by Olsen \& Associates, Switzerland. The database contains all the quotes that appear on the interbank Reuters network along with their times to the nearest even second.

Securities had to be continuously listed on both exchanges over the period February 1, 2001 through April 20, 2001 and had to trade at least once a day on either exchange during the period February 1, 2001 to February 28, 2001. Sixty-five securities satisfy these criteria; 24 of the firms listing these securities reported financial statements in US dollars and 41 reported in Canadian dollars. (Note 9) Throughout this study, all prices are stated in US dollars. Canadian prices are converted to their US equivalent using the most recent exchange rate quotes at or prior to the price time stamp.

Table I presents descriptive statistics for trades of securities cross-listed on the TSE and NYSE during the period March 1, 2001 through April 20, 2001. There are more than 1.3 million trades on the TSE and about 425,000 trades on the NYSE. Trades on the NYSE (average value of US\$46,098) tend to be larger than those on the TSE (average value of US\$25,300). Thus, about $63 \%$ of the total dollar volume of combined trading of cross-listed shares is on the TSE. In addition, the TSE has 16,441 block trades of the cross-listed securities versus 19,149 on the NYSE. The average price volatility of the securities included in the sample is $2.96 \%$.

Table I. Descriptive statistics for trades of securities cross-listed on the NYSE and TSE from March 1, 2001 through April 20, 2001

This table presents general descriptive statistics for all trades of securities cross-listed on the NYSE and TSE from March 1, 2001 through April 20, 2001. The data are extracted from the TSE Equity History files and the NYSE TAQ 
CD-ROMs. To be included, the cross-listed securities had to be continuously listed on both exchanges over the period February 1, 2001 through April 20, 2001. Securities which did not trade at least once a day on either exchange during the period February 1, 2001 to February 28, 2001 are excluded. For buyer-initiated trades, i) the total price impact is measured by the logarithm of trade price divided by the mean of the market quotes immediately prior to the trade, ii) the permanent price impact is measured by the logarithm of the mean of the market quotes 15 seconds after the trade to the mean of the market quotes immediately prior to the trade and iii) the temporary price impact is measured by the logarithm of trade price divided by the mean of the market quotes 15 seconds after the trade. For seller-initiated trades, the price impacts are the logarithm of the inverse of the ratios of those of the buyer-initiated trades. The Price Volatility variable is the standard deviation of daily returns in February 2001. The market capitalization of the firm is measured at the end of February 2001.

\begin{tabular}{|c|c|c|}
\hline \multirow[b]{2}{*}{ Variable } & \multicolumn{2}{|c|}{$\begin{array}{l}\text { Market on Which Trades o } \\
\text { Cross-Listed Stocks Occur }\end{array}$} \\
\hline & TSE & NYSE \\
\hline Number (Percentage) of Trades & $1,314,912(75.57 \%)$ & $425,008(24.43 \%)$ \\
\hline Millions (Percentage) of Shares Traded & $1,677(64.57 \%)$ & $921(35.43 \%)$ \\
\hline Value (Percentage) of Shares Traded in Millions of US\$ & $\$ 33,267(62.94 \%)$ & $\$ 19,593(37.06 \%)$ \\
\hline Number (Percentage) of Block Trades i.e. $\geq 10,000$ shares & $16,441(1.25 \%)$ & $19,149(4.51 \%)$ \\
\hline Mean (Standard Deviation) of Number of Shares in Trade & $1,276(13,300)$ & $2,166(8,914)$ \\
\hline Mean (Standard Deviation) of US\$ Value of Shares in Trade & $\$ 25,300(\$ 245,545)$ & $\$ 46,098(\$ 167,864)$ \\
\hline Time Weighted Average Spread in US cents & $\$ 0.1044$ & $\$ 0.1092$ \\
\hline $\begin{array}{l}\text { Mean of Depth at Best Quote on Opposite Side of Book Prior to } \\
\text { Trade (Number of Shares) }\end{array}$ & 4,820 & 3,337 \\
\hline Mean (Standard Deviation) of Total Price Impact of Trade & $0.150 \%(0.238 \%)$ & $0.110 \%(0.173 \%)$ \\
\hline Mean (Standard Deviation) of Permanent Price Impact of Trade & $0.063 \%(0.285 \%)$ & $0.054 \%(0.202 \%)$ \\
\hline Mean (Standard Deviation) of Temporary Price Impact of Trade & $0.087 \%(0.207 \%)$ & $0.056 \%(0.203 \%)$ \\
\hline $\begin{array}{l}\text { Trades where reporting currency is Canadian Dollar (Percentage of } \\
\text { Exchange Trades) }\end{array}$ & $716,113(54.46 \%)$ & $131,109(30.85 \%)$ \\
\hline Price Volatility of Cross-listed Firms & $2.955 \%$ & \\
\hline Mean Market Capitalization of Cross-listed Firms in US $\$$ billions & 5.154 & \\
\hline
\end{tabular}

We compare trade execution costs across the two exchanges. Trading costs are a combination of price impacts and commissions. Officials of the TSE indicate that the commissions for institutional trades of the same stocks on the same day on the NYSE and TSE are virtually identical. Thus, differences in trade execution costs are measured by differences in the price impact across the exchanges. The average total price impact of trades on the TSE is $0.150 \%$ versus $0.110 \%$ for trades on the NYSE. Thus, the mean total price impact of trades on the TSE is $0.04 \%$ higher than on the NYSE. On an average size trade of US $\$ 33,008$, the difference in price impact would be $\$ 13$, which is marginally economically significant. Most of this difference is attributable to the higher average temporary price impact of trades on the TSE $(0.087 \%)$ versus the NYSE $(0.056 \%)$. The average permanent price impacts are marginally higher on the TSE than the NYSE $(0.063 \%$ versus $0.054 \%)$. 
In measuring the price impact of a trade, we assume the perspective of a US investor who, when buying shares on the TSE, first must buy Canadian dollars by selling US dollars. As the US currency is quoted in Canadian dollars per US dollar, we use the foreign exchange bid quote to get a measure of the cost of buying the stock in US dollars. When selling shares on the TSE, since the proceeds of sale are Canadian dollars, we must convert these to US dollars at the foreign exchange ask quote. Because of the spread in the US/Canadian dollar exchange rate, our analysis should be biased against finding lower trade execution costs on the TSE. The average relative spread in the exchange rate over the period of study is $0.06 \%$. Taking half of this spread as the component of price impact attributable to converting Canadian into US dollars would account for almost all of the average cost disadvantage of the TSE of $0.04 \%$ noted above. Thus, the transaction costs on the NYSE and TSE based on trading at prices in domestic currencies are nearly identical.

If the two markets are highly integrated, the arbitrage opportunities will be infrequent, economically small and short lived. A summary of the arbitrage opportunities is presented in Table II. An arbitrage opportunity exists if the market bid in one market is above the market ask in the other. In such circumstances, the trader could potentially profit by simultaneously buying shares on the less expensive exchange at the ask and selling them at the bid on the more expensive exchange. However, we note that the arbitrage profits we report assume zero transaction cost and immediate and simultaneous order execution. Any lag in execution could result in shifts in either market quotes of the cross-listed stocks or in the Canadian/US dollar exchange rate. Such potential shifts mean that cross-border arbitrage activities are not riskless.

Table II. Descriptive statistics on arbitrage opportunities between the NYSE and TSE with cross-listed securities from March 1, 2001 through April 20, 2001

To be included, the cross-listed securities have to be continuously listed on both exchanges over the period February 1, 2001 through April 20, 2001. Securities which do not trade at least once a day on either exchange during the period February 1, 2001 to February 28, 2001 are excluded. Arbitrage opportunities occur when a stock that is cross-listed has an ask quote on one market that is less than the bid quote on the other market. A return is earned if you buy shares at the ask quote in the inexpensive market and simultaneously sell the same number of shares at the bid quote in the expensive market. The number of shares in an arbitrage opportunity is the lesser of the depth at these respective ask and bid quotes. The potential arbitrage return is expressed in basis points. The potential arbitrage returns and profits assume no transaction costs and no charge for potential failure to execute trades in a timely fashion. The duration of the arbitrage opportunity is the time that it was outstanding before it was taken or cleared.

Arbitrage Opportunities Between Markets

\begin{tabular}{|c|c|c|c|c|c|c|}
\hline $\begin{array}{l}\text { Market in which Arbitrage Opportunity is created } \\
\text { i.e. where Second Set of Quotes posted }\end{array}$ & Toronto & o Stocl & change & New Yo & rk Stock & xchange \\
\hline Number of Shares in Arbitrage Opportunity & $<1,000$ & $\begin{array}{l}1,000 \text { to } \\
10,000\end{array}$ & $>10,000$ & $<1,000$ & $\begin{array}{l}1,000 \text { to } \\
10,000\end{array}$ & $>10,000$ \\
\hline Average Potential Arbitrage Return (in basis points) & 10.363 & 8.512 & 8.96 & 10.566 & 10.051 & 11.049 \\
\hline Average Potential Arbitrage Profit (in \$US) & $\$ 7.34$ & $\$ 33.88$ & $\$ 168.56$ & $\$ 6.88$ & $\$ 36.96$ & $\$ 213.31$ \\
\hline $\begin{array}{l}\text { Average Duration of Arbitrage Opportunity (in } \\
\text { seconds) }\end{array}$ & 62.3 & 53.9 & 31.9 & 79.4 & 69.3 & 48.3 \\
\hline Number of Arbitrage Opportunities & 28,238 & 15,316 & 266 & 14,355 & 7,532 & 121 \\
\hline $\begin{array}{l}\text { Number of Arbitrage Opportunities as Percentage of } \\
\text { All Quotes on that Exchange }\end{array}$ & $1.33 \%$ & $0.72 \%$ & $0.01 \%$ & $0.79 \%$ & $0.42 \%$ & $0.01 \%$ \\
\hline
\end{tabular}

Table II shows that there are relatively few arbitrage opportunities and those that exist, do not offer much potential for profit and disappear quickly. In total, there are approximately 66,000 arbitrage opportunities which is small relative to the number of quotes. For about $2 \%$ of TSE quotes and $1.2 \%$ of NYSE quotes, there is potential for arbitrage profits. Furthermore, about two-thirds of these arbitrage opportunities are for fewer than 1,000 shares. In such cases, the average potential arbitrage profit is about $\$ 7$ which would provide a return of approximately 10 basis points. These arbitrage opportunities last on average just over a minute. Most of the remaining arbitrage 
opportunities are between 1,000 and 10,000 shares. In such cases, the arbitrage profit is about $\$ 35$ and duration of the arbitrage opportunity is shorter. Consequently, if one factors in two-way commission costs and an inability to always obtain immediate and simultaneous execution, it is safe to argue that the realizable arbitrage profits are very small for the stocks cross-listed on the Toronto and New York Stock Exchanges.

We next analyze whether trades are executed on the exchange with the best available prices. For each buyer-initiated (seller-initiated) trade, we investigate whether it could have been executed on the other exchange at a better price given the best available quoted ask (bid) price and depth. Trade direction is measured by the tick test.

As shown in Table III, $62.45 \%$ and $54.12 \%$ of TSE and NYSE trades, respectively, were executed on the exchange that provided better prices. However, for $29.64 \%$ of TSE trades and $33.22 \%$ of NYSE trades of the cross-listed securities, there were better quoted prices at sufficient depth on the other market. Thus, a large percentage of trades on both markets do not get best execution. They could have been executed on the other exchange at a better price.

Table III. An analysis of whether trading occurs in the market with the best execution from March 1, 2001 through April 20, 2001

This table analyzes whether trades of securities cross-listed on the NYSE and the TSE would have been executed at more favorable prices on the other exchange. To be included, the cross-listed securities had to be continuously listed on both exchanges over the period February 1, 2001 through April 20, 2001. Securities which did not trade at least once a day on either exchange during the period February 1, 2001 to February 28, 2001 are excluded. In particular, for trades on The Toronto Stock Exchange, Panel A shows the percentage that would have been executed at better, same and worse prices on the New York Stock Exchange based on available depth in the NYSE limit order book. For a buyer-motivated trade, a better price is defined as an ask quote in the limit book of the other exchange that is lower than the price of the trade. For a seller-motivated trade, a better price is defined as a bid quote in the limit book of the other exchange that is higher than the price of the trade. All trades of securities cross-listed from March 1, 2001 through April 20, 2001 on the New York and the Toronto stock exchanges are included in this table. There are 1,314,912 and 425,008 trades on the Toronto and the New York stock exchanges, respectively. All traded and quoted prices are converted into US dollars at the concurrent time-stamped exchange rate.

Panel A: Trades executed on Toronto Stock Exchange

\begin{tabular}{lllllll}
\hline \multirow{2}{*}{ Trade Size } & \multicolumn{2}{l}{ Sufficient Depth on NYSE } & \multicolumn{2}{l}{ Insufficient Depth on NYSE } \\
\cline { 2 - 7 } & \multicolumn{2}{l}{ NYSE Quote Relative to TSE Price } & \multicolumn{2}{l}{ NYSE Quote Relative to TSE Price } \\
\cline { 2 - 7 } & $\begin{array}{l}\text { NYSE } \\
\text { Better }\end{array}$ & $\begin{array}{l}\text { NYSE } \\
\text { Same }\end{array}$ & $\begin{array}{l}\text { NYSE } \\
\text { Worse }\end{array}$ & $\begin{array}{l}\text { NYSE } \\
\text { Better }\end{array}$ & $\begin{array}{l}\text { NYSE } \\
\text { Same }\end{array}$ & $\begin{array}{l}\text { NYSE } \\
\text { Worse }\end{array}$ \\
\hline$<1,000$ Shares & $26.20 \%$ & $0.01 \%$ & $43.53 \%$ & $3.45 \%$ & $0.00 \%$ & $4.37 \%$ \\
$1,000 \leq$ Shares $<10,000$ & $3.43 \%$ & $0.00 \%$ & $7.47 \%$ & $4.05 \%$ & $0.00 \%$ & $6.24 \%$ \\
$\geq 10,000$ Shares & $0.02 \%$ & $0.00 \%$ & $0.06 \%$ & $0.40 \%$ & $0.00 \%$ & $0.78 \%$ \\
\hline Total & $29.64 \%$ & $0.01 \%$ & $51.06 \%$ & $7.89 \%$ & $0.00 \%$ & $11.39 \%$ \\
\hline
\end{tabular}


Panel B: Trades executed on New York Stock Exchange

\begin{tabular}{lllllll}
\hline Trade Size & $\begin{array}{l}\text { Sufficient } \\
\text { Exchange }\end{array}$ & Depth on & Toronto Stock & $\begin{array}{l}\text { Insufficient } \\
\text { Stock Exchange }\end{array}$ & Depth on & Toronto \\
\cline { 2 - 7 } & \multicolumn{2}{c}{ TSE Quote Relative to NYSE Price } & TSE Quote Relative to NYSE Price \\
\cline { 2 - 7 } & TSE Better & $\begin{array}{l}\text { TSE } \\
\text { Same }\end{array}$ & TSE Worse & $\begin{array}{l}\text { TSE } \\
\text { Better }\end{array}$ & $\begin{array}{l}\text { TSE } \\
\text { Same }\end{array}$ & $\begin{array}{l}\text { TSE } \\
\text { Worse }\end{array}$ \\
\hline 1,000 Shares & $24.81 \%$ & $0.00 \%$ & $29.54 \%$ & $2.47 \%$ & $0.00 \%$ & $2.66 \%$ \\
$1,000 \leq$ Shares $<10,000$ & $8.28 \%$ & $0.00 \%$ & $10.01 \%$ & $8.19 \%$ & $0.00 \%$ & $9.53 \%$ \\
\hline 10,000 Shares & $0.13 \%$ & $0.00 \%$ & $0.13 \%$ & $1.99 \%$ & $0.00 \%$ & $2.26 \%$ \\
\hline Total & $33.22 \%$ & $0.00 \%$ & $39.67 \%$ & $12.65 \%$ & $0.00 \%$ & $14.45 \%$ \\
\hline
\end{tabular}

Another factor that should affect trade location is the market which can supply more liquidity to the side of the trade that corresponds to the liquidity-seeking order. While it would be most useful to have information on the full side of a limit order book, the only available information on the NYSE order book is the best market quote. Thus, we use the depth of the best market quote to measure available liquidity. Panel B of Table III indicates that the NYSE handles a higher concentration of larger orders. More than $25 \%$ of NYSE trades could not have been executed on the TSE without changing the price due to insufficient volume at the market. Less than $20 \%$ of the TSE trades would have had a similar problem on the NYSE.

The results in Table III motivate the need to do an analysis that incorporates other factors affecting trade location rather than price alone. We use a logit regression to estimate the following equation for the period, March 1, 2001 to April 20, 2001:

$$
\text { Exch }_{i, j}=f\left(N Y S E V \operatorname{Rel}_{i, j}, \text { TSEVRel }_{i, j} \text { PriceRel }_{i, j}, \text { Domestic }_{i, j}\right)
$$

where,

Exch $_{i, j} \quad=\quad 1$ if on TSE and 0 if on NYSE

NYSEVRel $_{i, j} \quad=\quad$ number of shares in trade $\mathrm{j}$ for security $\mathrm{i}$ divided by number of shares at ask (bid) on NYSE immediately prior to trade $\mathrm{j}$ for buyer- (seller-) initiated trades

TSEVRel $_{i, j} \quad=\quad$ number of shares in trade $\mathrm{j}$ for security i divided by number of shares at ask (bid) on TSE immediately prior to trade $\mathrm{j}$ for buyer- (seller-) initiated trades

PriceRel $_{i, j} \quad=\quad$ ask price on the TSE divided by ask price on the NYSE immediately prior to trade $\mathrm{j}$ for security $\mathrm{i}$ for buyer-initiated trades; bid price on the NYSE divided by bid price on the TSE immediately prior to trade $\mathrm{j}$ for security $\mathrm{i}$ for seller-initiated trades

Domestic $_{i, j} \quad=\quad 1$ if financial statements of company listing security $\mathrm{i}$ are reported in Canadian dollars and 0 otherwise.

We expect the coefficient of NYSEVRel ${ }_{i, j}$ to be significantly positive as a large trade relative to the order book on the NYSE suggests that the NYSE is less able to absorb the trade. The trade is more likely to occur on the TSE. On the other hand, we expect the coefficient of $T S E V R e l_{i, j}$ to be significantly negative as a larger order relative to volume of the TSE would suggest the TSE is less able to absorb the trade and we expect it is more likely to be executed on the NYSE. PriceRel $l_{i, j}$ measures the price competitiveness of one market versus the other. If, from the perspective of the trade initiator, the TSE's price is worse than that available on the NYSE, PriceRel $l_{i, j}$ will be greater than one and we would expect the trade to go to the NYSE. The coefficient on PriceRel $_{i, j}$ should be negative. Domestic $c_{i, j}$ is expected to reflect where the majority of investors are domiciled. We expect firms that report in Canadian dollars to be predominately owned by Canadian shareholders and traded on the TSE. Likewise, we expect firms that report in US 
dollars to be mainly owned by Non-Canadian residents and traded on the NYSE. Thus, the coefficient on Domestic $c_{i, j}$ is expected to be positive.

The results of the logit regression, shown in Table IV, indicate that stocks trade in the market that offers greater liquidity. In particular, if the trade size is high relative to the depth of the limit order book at the market on the NYSE, then the stock tends to trade in Toronto. Likewise, if the trade size is high relative to the depth of the limit order book on the TSE, then the trade is less likely to occur on the TSE. If the quoted stock price at the market is better on the TSE than the NYSE, the trade is more likely to occur on the TSE. All of these findings suggest that the market is highly responsive to shifts in liquidity from one market to the other. Finally, if a company reports its financial statements in Canadian dollars, then it is likely that the firm's stock will trade on the TSE. This suggests that the residency of the majority of the firm's shareholders has a significant impact on choice of trading venue.

Table IV. Logit regression model of likelihood of trade of securities cross-listed on the TSE and NYSE being executed on TSE from March 1, 2001 through April 20, 2001

This table shows coefficients, standard errors, and z-statistics of a logit regression model for trades of 65 stocks cross-listed on the TSE and NYSE during the period from March 1, 2001 to April 20, 2001. To be included, the cross-listed securities had to be continuously listed on both exchanges over the period February 1, 2001 through April 20, 2001. Securities which did not trade at least once a day on either exchange during the period February 1, 2001 to February 28, 2001 are excluded. One, two, and three asterisks indicate significance at the 5-percent, 1-percent, and 0.1-percent levels, respectively.

where,

$$
\text { Exch }_{i, j}=f\left(\text { NYSEVRel }_{i, j}, \text { TSEVRel }_{i, j}, \text { PriceRel }_{i, j}, \text { Domestic }_{i, j}\right)
$$

Exch $_{i, j} \quad=\quad 1$ if trade is on TSE and 0 if trade is on NYSE

NYSEVReli, $j=$ number of shares in trade $\mathrm{j}$ for security $\mathrm{i}$ divided by number of shares at ask (bid) on NYSE immediately prior to trade $\mathrm{j}$ for security $\mathrm{i}$ for buyer- (seller-) initiated trades

TSEVReli $j=$ number of shares in trade $\mathrm{j}$ for security $\mathrm{i}$ divided by number of shares at ask (bid) on TSE immediately prior to trade $\mathrm{j}$ for security $\mathrm{i}$ for buyer- (seller-) initiated trades

PriceReli, $j \quad=\quad$ (ask price on the TSE / ask price on the NYSE) immediately prior to trade $\mathrm{j}$ for security $\mathrm{i}$ for buyer-initiated trades; (bid price on the NYSE / bid price on the TSE) immediately prior to trade $\mathrm{j}$ for security $\mathrm{i}$ for seller-initiated trades

Domestic $_{i, j} \quad=\quad 1$ if financial statements of company listing security $i$ are reported in Canadian dollars and 0 otherwise.

\begin{tabular}{llll}
\hline & Coefficient & Std. Error & z-statistic \\
\hline Constant & 0.9110 & 0.027563 & $33.05^{* * *}$ \\
NYSEVRel $_{i, j}$ & 0.0009 & $9.13 \mathrm{E}-05$ & $10.28^{* * *}$ \\
TSEVRel $_{i, j}$ & -0.0108 & 0.000251 & $-42.92^{* * *}$ \\
PriceRel $_{i, j}$ & -0.1864 & 0.027477 & $-6.78^{* * *}$ \\
Domestic $_{i, j}$ & 0.9818 & 0.003762 & $260.98^{* * *}$ \\
McFadden's R-squared & 0.0394 & & \\
Number of Trades & $1,739,255$ & & \\
\hline
\end{tabular}

While Table IV suggests that clientele effects exist among Canadian investors, Table III is consistent with clientele effects affecting investors in both the TSE and NYSE. To the extent that these clientele effects are approximately the same in each market, one expects transaction costs to be the same on average. As noted earlier, Table I suggests that transaction costs show little material difference between the two exchanges.

We also hypothesize that trading occurs on the exchange with the highest quality. A cross-sectional regression is run for the estimation period, March 1, 2001 to April 20, 2001. 


$$
\begin{aligned}
& \text { Ln(Total Volume on TSE / Total Volume on NYSE })= \\
& k_{0}+k_{1} * \text { AvgPrice } e_{i}+k_{2} * A v g \text { Aol }_{i}+k_{3} * \text { LRCont }_{t}+e_{t}
\end{aligned}
$$

where

AvgPrice $_{i} \quad=\quad(($ Percentage of time TSE has a bid at least as high as NYSE $)+($ Percentage of time TSE has an ask quote at least as low as NYSE))/2

AvgVol $_{i} \quad=\quad$ (Percentage of time TSE has an offered volume at least as large as NYSE) $+($ Percentage of time TSE has a wanted volume at least as large as NYSE))/2

LRCont $_{i} \quad=\quad \ln$ (percentage of trades on TSE that resulted in a price change of one US cent or less/percentage of trades on the NYSE that resulted in a price change of one US cent or less)

We expect that there is a positive relationship between each of the variables AvgPrice ${ }_{i}$, Avg Vol $_{i}$ and LRCont $_{i}$ and the relative volume on the TSE versus the NYSE. That is, more trading takes place on the TSE versus the NYSE when the market offers more favorable quote prices and depth. The variable LRCont $_{i}$ is included in the analysis because total order flow, not just displayed volume and prices, is an important dimension of market quality.

Table $\mathrm{V}$ reports the results of a cross-sectional regression of the relative volume of trading on the TSE versus the NYSE on three variables that reflect market quality. (Note 10) We find that trading is more likely to occur on the TSE when the prices are more attractive. In addition, trading is more likely to happen in Canada when the depth of the limit order book at the market is superior on the TSE than NYSE. Finally, if there is greater price continuity on a stock on the TSE than the NYSE, trading is more likely to occur on the TSE. Overall, the results suggest that market quality is a significant determinant of whether trading occurs on the TSE or the NYSE.

Table V. Regression model of proportion of trades of securities cross-listed on the TSE and NYSE being executed on the TSE from March 1, 2001 through April 20, 2001

This table shows coefficients, standard errors, and t-statistics of a cross-sectional regression model to explain the proportion of trading done on the TSE relative to that done on the NYSE across 65 cross-listed securities during the period from March 1, 2001 to April 20, 2001. To be included, the cross-listed securities had to be continuously listed on both exchanges over the period February 1, 2001 through April 20, 2001. Securities which did not trade at least once a day on either exchange during the period February 1, 2001 to February 28, 2001 are excluded. One, two, and three asterisks indicate significance at the 5-percent, 1-percent, and 0.1-percent levels, respectively. Model estimated using heteroskedasticity-consistent standard errors and covariance.

$$
\begin{gathered}
\text { Ln(Total Volume on TSE / Total Volume on NYSE) }= \\
k_{0}+k_{1} * \text { AvgPrice }_{i}+k_{2} * \text { AvgVol }_{i}+k_{3} * \text { LRCont }_{t}+e_{t}
\end{gathered}
$$

where for stock $\mathrm{i}$

AvgPrice $_{i}=(($ Percentage of time TSE has a bid price at least as high as NYSE $)+($ Percentage of time TSE has an ask price at least as low as NYSE) $) / 2$

AvgVol $_{i} \quad=\quad($ Percentage of time TSE has an offered volume at least as large as NYSE) $+($ Percentage of time TSE has a wanted volume at least as large as NYSE))/2

LRCont $_{i}=\ln$ (percentage of trades on TSE that resulted in a price change of 1 US cent or less/percentage of trades on the NYSE that resulted in a price change of 1 US cent or less)

\begin{tabular}{llll}
\hline & Coefficient & Std. Error & t-statistic \\
\hline Constant & -5.1122 & 0.484195 & $-10.56^{* * *}$ \\
AvgPrice $_{i}$ & 0.0500 & 0.007198 & $6.95 * * *$ \\
AvgVol $_{i}$ & 0.0512 & 0.006571 & $7.80^{* * *}$ \\
LRCont $_{i}$ & 1.7265 & 0.399718 & $4.32^{* * *}$ \\
Adjusted R-Squared $_{\text {Number of Securities }}$ & 0.8902 & & \\
Numb & 65 & & \\
\hline
\end{tabular}


We next test the hypothesis that the trade execution costs of the NYSE and the TSE are not significantly different after adjusting for differences in trade size, price volatility and firm size. The regression of price impact on explanatory factors, including the choice of trading venue is as follows: (Note 11)

$$
\begin{gathered}
O_{i, j}=C_{0}+C_{1} \text { TradeSize }_{i, j}+C_{2} \text { PriceVol }_{i, j}+C_{3} \text { FirmSize }_{i, j}+ \\
C_{4} \text { TSE }_{i, j}+C_{5} \text { TSE }_{i, j} * \text { TradeSize }_{i, j}+e_{i, j}
\end{gathered}
$$

where

$O i, j=\ln (P i, j / E i, j)$ for buyer-initiated trades and $\ln (E i, j / P i, j)$ for seller-initiated trades: price impact of trade $\mathrm{j}$ for stock $\mathrm{i}$

$E_{i, j} \quad=$ the mean of the best bid-ask prices immediately before trade $\mathrm{j}$ for stock $\mathrm{i}$ translated into US dollars using the midquote of the Canadian/US dollar exchange rate (Note 12)

$P_{i, j} \quad=\quad$ the price of trade $\mathrm{j}$ for stock $\mathrm{i}$ in US dollars

TradeSize $_{i, j}=$ the trade size divided by the median daily number of shares traded over all trading days during

February 2001

PriceVol $_{i, j}=$ the standard deviation of the daily return (US\$) on the stock during February 2001

FirmSize $_{i, j} \quad=\ln$ of the US dollar market capitalization of the firm as of February 28, 2001

$T S E_{i, j} \quad=$ dummy variable equal to one if trade is on TSE and zero otherwise

Consistent with Easley and O'Hara (1987), we expect $C_{1}$ to be positive. That is, informed traders will place larger orders to profit from any informational advantage they hold. Given the evidence from Burdett and O'Hara (1987) and Seppi (1990), larger order execution costs are expected for larger trades. As in Griffiths, Smith, Turnbull and White (2000), the coefficient for PriceVol, $\mathrm{C}_{2}$, is expected to be positive. Greater volatility means that a stock is riskier to hold in a market maker's inventory because of potential holding losses. Higher order execution costs compensate liquidity providers for this risk. Thus, greater price volatility is expected to increase order execution costs. The coefficient for FirmSize is expected to be negative because information content is expected to be greater for smaller firms. If the fixed and variable costs of executing a trade on the TSE are lower than on NYSE, the sign of the coefficients, $\mathrm{C}_{4}$ and $\mathrm{C}_{5}$, respectively, should be negative.

As expected, Table VI shows that trade size and price volatility are positively related to total price impact of trades. Also, firm size is negatively related to the total price impact of trades. For all trades, the fixed component of total price impact is significantly higher on the TSE than the NYSE after controlling for differences in trade size, price volatility and market capitalization. In contrast, the variable component of total price impact is significantly negative. This means that for large trades (trade size more than $4 \%$ of median daily number of shares traded), the TSE is less expensive. These results also hold for the sample of non-block trades. For the sample of block trades, the TSE is less expensive as both fixed and variable components of total price are significantly negative.

Table VI. Regression analysis of determinants of total price impact of trades for cross-listed securities from March 1, 2001 through April 20, 2001

This table shows the coefficients (multiplied by 100), standard errors (in parentheses) and adjusted $\mathrm{R}^{2}$ of regression (3) for trades on the TSE and NYSE for cross-listed securities in the period from March 1, 2001 to April 20, 2001. To be included, the cross-listed securities had to be continuously listed on both exchanges over the period February 1, 2001 through April 20, 2001. Securities which did not trade at least once a day on either exchange during the period February 1, 2001 to February 28, 2001 are excluded One, two, and three asterisks indicate significance at the 5-percent, 1-percent, and 0.1-percent levels, respectively. Model estimated using heteroskedasticity-consistent standard errors and covariance. The model for price impact of a trade is:

$$
\begin{gathered}
O_{i, j}=C_{0}+C_{1} \text { TradeSize }_{i, j}+C_{2} \text { PriceVol }_{i, j}+C_{3} \text { FirmSize }_{i, j}+ \\
C_{4} \text { TSE }_{i, j}+C_{5} \text { TSE }_{i, j} * \text { TradeSize }_{i, j}+e_{i, j}
\end{gathered}
$$

$O_{i, j} \quad=\quad \ln \left(P_{i, j} / E_{i, j}\right)$ for buyer-initiated trades and $\ln \left(E_{i, j} / P_{i, j}\right)$ for seller-initiated trades: price impact of trade $\mathrm{j}$ for stock $\mathrm{i}$

$E_{i, j} \quad=\quad$ the mean of the best bid-ask prices immediately before trade $\mathrm{j}$ for stock $\mathrm{i}$

$P_{i, j} \quad=\quad$ the price of trade $\mathrm{j}$ for stock $\mathrm{i}$

TradeSize $_{i, j}=$ the trade size divided by the median daily number of shares traded over all trading days during 
February 2001

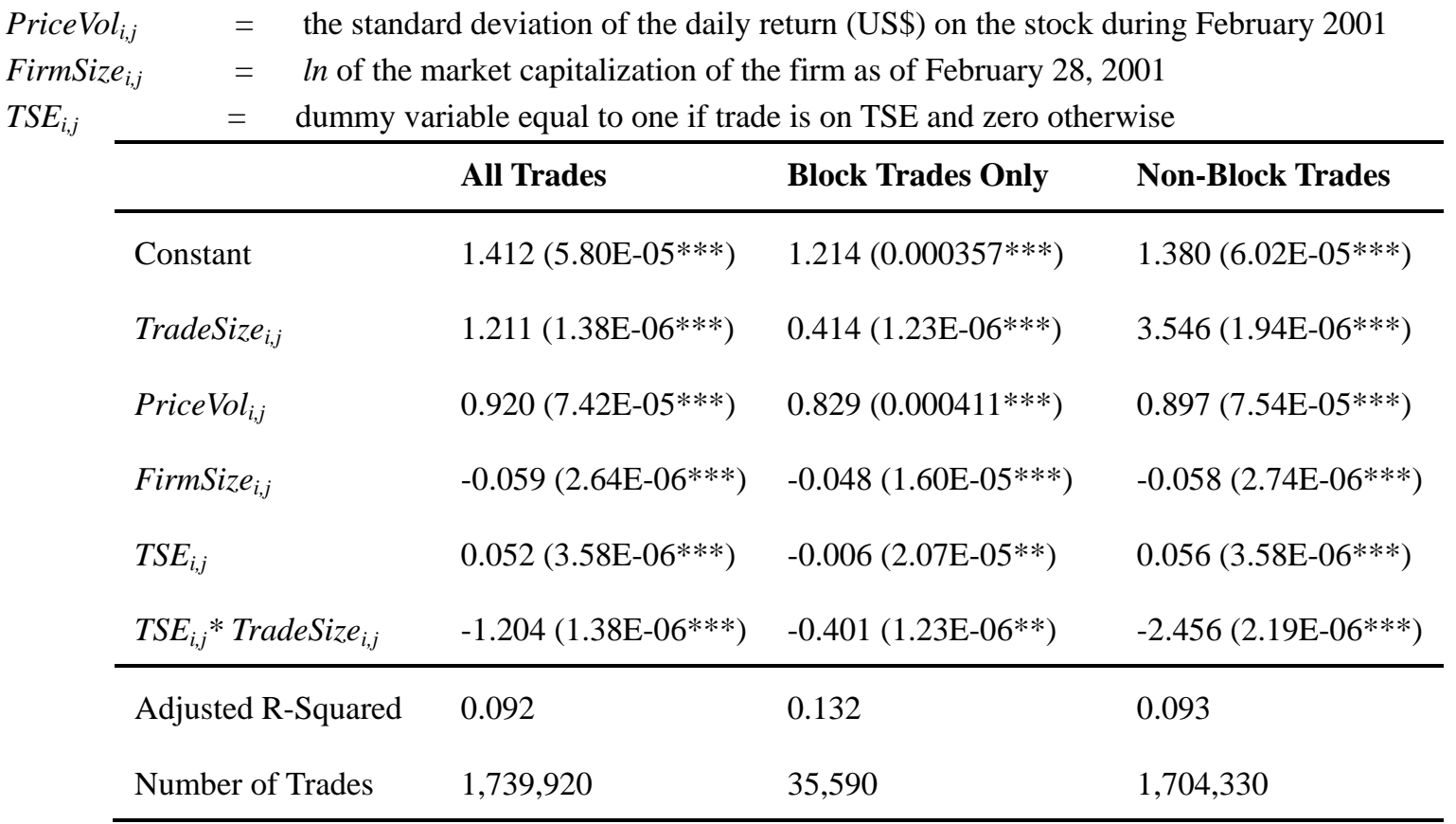

We attribute lower cost on small trades on the NYSE to the clientele effects in that most of the smaller trades appear to be for Canadian retail investors who choose to trade on the TSE despite potentially higher price impacts. To a Canadian retail investor, the smaller price impacts on the NYSE would be offset by foreign currency conversion costs as well as potentially higher commissions. The slightly lower cost of the block trades of the TSE is consistent with the effectiveness of the TSE upstairs market in screening out information-based orders.

Regressions with the same independent variables are also run to compare the temporary and permanent price effects across the exchanges. The temporary effect is measured as $\ln \left(P_{i, j} / A_{i, j}\right)$ for buyer-initiated trades and $\ln \left(A_{i, j} / P_{i, j}\right)$ for seller-initiated trades where $A_{i, j}$ is the mean of the best bid-ask prices 15 seconds after trade $\mathrm{j}$ for stock i. The permanent price effect is measured as $\ln \left(A_{i, j} / E_{i, j}\right)$ for buyer-initiated trades and $\ln \left(E_{i, j} / A_{i, j}\right)$ for seller-initiated trades. It is expected that differences in the structure of the upstairs markets lead to differences in search costs which in turn lead to differences in temporary price effects for larger trades. Furthermore, the rules of the TSE which facilitate more upstairs market-making may lead to lower information costs given the non-anonymous trading environment upstairs.

Table VII shows that the results for the temporary price impacts are similar to those for the total price impact with one exception. The fixed component of the temporary price impact for block trades is higher on the TSE. This is consistent with the higher fixed search costs for block trades on the TSE than NYSE as proportionately more trades go through the upstairs market mechanism on the TSE than on the NYSE. Madhavan and Cheng (1997) report higher fixed costs in the upstairs market.

Table VII. Regression analysis of determinants of temporary price impacts of trades for cross-listed securities March 1, 2001 through April 20, 2001

This table shows the coefficients (multiplied by 100), standard errors (in parentheses) and adjusted $\mathrm{R}^{2}$ of regression of temporary price impact for trades on the TSE and NYSE for cross-listed securities in the period from March 1, 2001 to April 20, 2001. To be included, the cross-listed securities had to be continuously listed on both exchanges over the period February 1, 2001 through April 20, 2001. Securities which did not trade at least once a day on either exchange during the period February 1, 2001 to February 28, 2001 are excluded. One, two, and three asterisks indicate significance at the 5-percent, 1-percent, and 0.1-percent levels, respectively. Model estimated using heteroskedasticity-consistent standard errors and covariance. The model for temporary price impact of a trade is:

$$
L_{i, j}=C_{0}+C_{1} \text { TradeSize }_{i, j}+C_{2} \text { PriceVol }_{i, j}+C_{3} \text { FirmSize }_{i, j}+
$$




$$
C_{4} T S E_{i, j}+C_{5} T S E_{i, j} * \operatorname{TradeSize}_{i, j}+e_{i, j}
$$

$L_{i, j} \quad=\quad \ln \left(P_{i, j} / A_{i, j}\right)$ for buyer-initiated trades and $\ln \left(A_{i, j} / P_{i, j}\right)$ for seller-initiated trades: price impact of trade $\mathrm{j}$ for stock $\mathrm{i}$

$P_{i, j} \quad=\quad$ the price of trade $\mathrm{j}$ for stock $\mathrm{i}$

$A_{i, j} \quad=\quad$ the mean of the best bid-ask prices 15 seconds after trade $\mathrm{j}$ for stock $\mathrm{i}$

TradeSize $_{i, j}=$ the trade size divided by the median daily number of shares traded over all trading days during February 2001

PriceVol $_{i, j}=$ the standard deviation of the daily return (US\$) on the stock during February 2001

FirmSize $_{i, j}=\ln$ of the market capitalization of the firm as of February 28, 2001

$T S E_{i, j} \quad=\quad$ dummy variable equal to one if trade is on TSE and zero otherwise

\begin{tabular}{|c|c|c|c|}
\hline & All Trades & Block Trades Only & Non-Block Trades \\
\hline Constant & $0.762\left(6.32 \mathrm{E}-05^{* * *}\right)$ & $0.724(0.000544 * * *)$ & $0.790\left(6.67 \mathrm{E}-05^{* * *}\right)$ \\
\hline TradeSize $_{i, j}$ & $0.612(1.13 \mathrm{E}-06 * * *)$ & $0.274\left(1.18 \mathrm{E}-06^{*}\right)$ & $1.352\left(2.80 \mathrm{E}-06^{* * *}\right)$ \\
\hline PriceVol $_{i, j}$ & $0.341(6.08 \mathrm{E}-05 * * *)$ & $0.465(0.000532 * * *)$ & $0.345\left(6.13 \mathrm{E}-05^{* * *}\right)$ \\
\hline FirmSize $_{i, j}$ & $-0.032(2.83 \mathrm{E}-06 * * *)$ & $-0.030(2.42 \mathrm{E}-05 * * *)$ & $-0.033(2.96 \mathrm{E}-06 * * *)$ \\
\hline$T S E_{i, j}$ & $0.038(3.66 \mathrm{E}-06 * * *)$ & $0.030(2.71 \mathrm{E}-05 * * *)$ & $0.041(4.23 \mathrm{E}-06 * * *)$ \\
\hline $\operatorname{TSE}_{i, j} *$ TradeSize $_{i, j}$ & $-0.607(1.15 \mathrm{E}-06 * * *)$ & $-0.262\left(1.15 \mathrm{E}-06^{*}\right)$ & $-3.115(3.11 \mathrm{E}-06 * * *)$ \\
\hline Adjusted R-Squared & 0.036 & 0.052 & 0.037 \\
\hline Number of Trades & $1,739,920$ & 35,590 & $1,704,330$ \\
\hline
\end{tabular}

As shown in Table VIII, the permanent price impacts exhibit a pattern that is also similar to that of the total price impact. That is, non-block trades are less expensive on the NYSE, whereas, the block trades are less expensive on the TSE. Both the fixed and variable components of the permanent price impacts are significantly negative (positive) for block (non-block) trades. This is consistent with the argument that the upstairs market on the TSE is effective in screening out information based orders. (Note 13)

Table VIII. Regression analysis of determinants of permanent price impact of trades for cross-listed securities March 1, 2001 through April 20, 2001

This table shows the coefficients (multiplied by 100), standard errors (in parentheses) and adjusted $\mathrm{R}^{2}$ of regression analysis of permanent price impact for trades on the TSE and NYSE for cross-listed securities in the period from March 1, 2001 to April 20, 2001. To be included, the cross-listed securities had to be continuously listed on both exchanges over the period February 1, 2001 through April 20, 2001. Securities which did not trade at least once a day on either exchange during the period February 1, 2001 to February 28, 2001 are excluded. One, two, and three asterisks indicate significance at the 5-percent, 1-percent, and 0.1-percent levels, respectively. Model estimated using heteroskedasticity-consistent standard errors and covariance. The model for permanent price impact of a trade is:

$$
\begin{gathered}
I_{i, j}=C_{0}+C_{1} \text { TradeSize }_{i, j}+C_{2} \text { PriceVol }_{i, j}+C_{3} \text { FirmSize }_{i, j}+ \\
C_{4} \text { TSE }_{i, j}+C_{5} \text { TSE }_{i, j} * \text { TradeSize }_{i, j}+e_{i, j}
\end{gathered}
$$

where:

$I_{i, j} \quad=\quad \ln \left(A_{i, j} / E_{i, j}\right)$ for buyer-initiated trades and $\ln \left(E_{i, j} / A_{i, j}\right)$ for seller-initiated trades: price impact of trade $\mathrm{j}$ for stock $\mathrm{i}$

$A_{i, j} \quad=\quad$ the mean of the best bid-ask prices 15 seconds after trade $\mathrm{j}$ for stock $\mathrm{i}$ 
TradeSize $_{i, j}=$ the trade size divided by the median daily number of shares traded over all trading days during February 2001

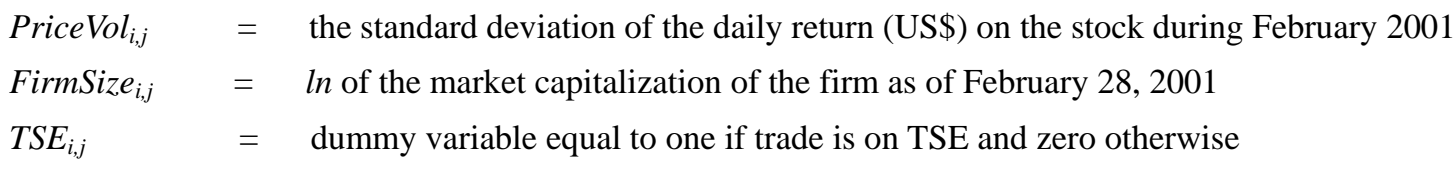

\begin{tabular}{llll}
\hline & All Trades & Block Trades Only & Non-Block Trades \\
\hline Constant & $0.650\left(6.67 \mathrm{E}-05^{* * *}\right)$ & $0.490\left(0.000409^{* * *}\right)$ & $0.589\left(7.08 \mathrm{E}-05^{* * *}\right)$ \\
TradeSize $_{i, j}$ & $0.599\left(9.37 \mathrm{E}-07^{* * *}\right)$ & $0.141\left(6.33 \mathrm{E}-07^{*}\right)$ & $2.193\left(2.53 \mathrm{E}-06^{* * *}\right)$ \\
PriceVol $_{i, j}$ & $0.579\left(8.21 \mathrm{E}-05^{* * *}\right)$ & $0.365\left(0.000421^{* * *}\right)$ & $0.552\left(8.36 \mathrm{E}-05^{* * *}\right)$ \\
FirmSize $_{i, j}$ & $-0.027\left(3.04 \mathrm{E}-06^{* * *}\right)$ & $-0.019\left(1.82 \mathrm{E}-05^{* * *}\right)$ & $-0.025\left(3.20 \mathrm{E}-06^{* * *}\right)$ \\
TSE $_{i, j}$ & $0.014\left(4.07 \mathrm{E}-06^{* * *}\right)$ & $-0.037\left(2.22 \mathrm{E}-05^{* * *}\right)$ & $0.015\left(4.56 \mathrm{E}-06^{* * *}\right)$ \\
TSE $_{i, j} *$ TradeSize $_{i, j}$ & $-0.596\left(9.48 \mathrm{E}-07^{* * *}\right)$ & $-0.139\left(6.11 \mathrm{E}-07^{*}\right)$ & $0.659\left(2.84 \mathrm{E}-06^{*}\right)$ \\
\hline Adjusted R-Squared & 0.013 & 0.027 & 0.015 \\
Number of Trades & $1,739,920$ & 35,590 & $1,704,330$ \\
\hline
\end{tabular}

\section{Conclusion}

This paper measures the impact of market quality and clientele effects on trading activity and trade execution costs of 65 stocks cross-listed and actively traded on both the NYSE and the TSE.

We find that approximately $30 \%$ of the trades on the TSE and 33\% of the trades on the NYSE could have been executed on the other exchange at a better price. However, in the majority of trades, on the other exchange, there was either a worse price or insufficient depth to handle the order. Thus, the evidence indicates that while there are clientele effects present in the markets, most traders appear to treat the two markets in an integrated approach. They select the market with the best available price and depth for their trade.

A logit regression of the factors associated with a trade occurring on the TSE rather than the NYSE also illustrates that, consistent with the implications of the order splitting models of Bernhardt and Hughson (1997) and Biais, Martimort and Rochet (2000), trading gravitates to the exchange with superior market quality. Trades tend to occur in the market that offers better quoted prices and depth. However, after controlling for these factors measuring market quality, the trades of stocks of firms which report their financial reports in Canadian (US) dollars are more likely to be executed on the TSE (NYSE). This is further evidence of a clientele effect. Some investors prefer to trade in their home market.

As a further test of the issue of choice of trading venue, we conduct a cross-sectional regression on the relative amount of trading done on the TSE versus the NYSE across stocks and find a larger proportion of trading in a stock is done on the exchange which, on average, offers better prices and depth in its limit order book for that stock. In addition, trading tends to occur on the exchange which offers superior price continuity.

These results have policy implications. First, if an exchange wants to attract volume, it should encourage or regulate tighter quoted spreads. More specifically, it could impose penalties on the market maker if market quotes are wider than on competing exchanges where the stocks are cross-listed. The exchange should also encourage greater revealed depth at the market. For example, on the NYSE, the orders in the specialist's book should be exposed and combined with the limit order book to attract more volume from competing exchanges. Finally, the significance of price continuity in attracting volume suggests that market makers play an important role through creating a more orderly market. 
From the perspective of a US investor, the average total price impact of all trades on the TSE is $0.15 \%$ versus $0.11 \%$ for the NYSE. This cost difference of four basis points is approximately equal to half of the average of the foreign exchange spread. Consequently, it is unlikely to be economically significant. We find statistically significant lower price impacts for the non-block trades on the NYSE after controlling for differences in trade size, price volatility and firm size. However, for block trades, the total and permanent price impacts are lower on the TSE than the NYSE. The lower permanent price impact of the block trades on the TSE is consistent with the efficient screening of information-laden orders in the upstairs market of that exchange. These results are consistent with the argument that the price improvement occurs in the downstairs market on the NYSE versus the upstairs market on the TSE.

In summary, our results suggest that fragmented markets can coexist even when there are few barriers to cross-border trading and the markets are so integrated that arbitrage opportunities are negligible and average transaction costs are equal across the exchanges. Consistent with the predictions of Chowdhry and Nanda (1991), domestic exchanges meet the needs of a subset of local investors based on clientele effects while at the same time competing with other exchanges on the basis of market quality. A single global exchange is not inevitable.

\section{Acknowledgment}

The author acknowledges The Toronto Stock Exchange for allowing access to the data used in this study. I thank Jon Cockerline, Director of Research at The Toronto Stock Exchange and John Murray, Adviser to the Governor, at the Bank of Canada for their assistance.

\section{References}

Bernhardt, D., \& E. Hughson. (1997). Splitting orders. Review of Financial Studies, 10, 69-101. https://doi.org/10.1093/rfs/10.1.69

Biais, B., D. Martimort, \& J.C. Rochet. (2000). Competing mechanisms in a common value environment. Econometrica, 68, 799-837. https://doi.org/10.1111/1468-0262.00138

Burdett, K., \& M. O'Hara. (1987). Building blocks: an introduction to block trading. Journal of Banking and Finance, 11, 193-212. https://doi.org/10.1016/0378-4266(87)90049-5

Chowdhry, B., \& V. Nanda. (1991). Multimarket trading and market liquidity. Review of Financial Studies, 4, 483-511. https://doi.org/10.1093/rfs/4.3.483

Easley, D., \& M. O'Hara. (1987). Price, trade size and information in securities markets. Journal of Financial Economics, 19, 69-90. https://doi.org/10.1016/0304-405X(87)90029-8

Griffiths, M. D., \& R. W. White. (1993). Tax induced trading and the turn-of-the-year anomaly: an intraday study. Journal of Finance, 19, 1265-1284. https://doi.org/10.1111/j.1540-6261.1993.tb04728.x

Griffiths, M. D., B. F. Smith, D. A. Turnbull, \& R. W. White. (2000). The costs and determinants of order aggressiveness. Journal of Financial Economics, 56, 65-68. https://doi.org/10.1016/S0304-405X(99)00059-8

Hasbrouck, J., G. Sofianos, \& D. Sosebee. (1993). New York Stock Exchange systems and trading Procedures. NYSE Working Paper \#93-01. Retrtrieved from: http://citeseerx.ist.psu.edu/viewdoc/download?doi=10.1.1.132.5638\&rep=rep1\&type=pdf on 11/28/2017

Jacquillat, B., \& C. Gresse. (1998). The diversion of order flow on French stocks from CAC to SEAQ International: a field study. European Financial Management, 4, 121-142. https://doi.org/10.1111/1468-036X.00060

Keim, D. B., \& A. Madhavan. (1996). The upstairs market for large-block transactions: analysis and measurement of price effects. Review of Financial Studies, 9, 1-36. https://doi.org/10.1093/rfs/9.1.1

Madhavan, A., \& M. Cheng. (1997). In search of liquidity: block trades in the upstairs and downstairs market. Review of Financial Studies, 10, 175-203. https://doi.org/10.1093/rfs/10.1.175

Pagano, M. (1989). Trading and Asset Liquidity. Quarterly Journal of Economics, 104, 483-511. https://doi.org/10.2307/2937847

Pulatkonak, M., \& G. Sofianos. (1999). The distribution of global trading in NYSE-listed non-US stocks. NYSE Working Paper 99-03. Retrieved from: https://www.nyse.com/pdfs/wp99-03.pdf.

Ready, M. (1999). The specialist's discretion: stopped orders and price improvement. Review of Financial Studies, 12, 1075-1112. https://doi.org/10.1093/rfs/12.5.1075 
Seppi, D. (1990). Equilibrium block trading and asymmetric information. Journal of Finance, 45, 73-94. https://doi.org/10.1111/j.1540-6261.1990.tb05081.x

Smith, B. F., D. A. Turnbull, \& R. W. White. (2001). Upstairs Market for Principal and Agency Trades: Analysis of Adverse Information and Price Effects. Journal of Finance, 56, 1723-1746. https://doi.org/10.1111/0022-1082.00387

Zellner, A. (1984). Basic Issues in Econometrics, The University of Chicago Press, Chicago.

\section{Notes}

Note 1. Of the approximately 400 foreign-based securities listed on the NYSE in 2001, 75 are Canadian-based securities listed on The Toronto Stock Exchange (TSE). International cross-listing of securities is a growing phenomenon. The amount of cross-listing by non-US companies on the New York Stock Exchange (NYSE) has tripled from 1996 to 2001.

Note 2. For example, in Canada some retail brokers charge higher commissions on trades executed on the NYSE than the TSE. For example, TD Waterhouse charges Canadian investors a flat fee of $\$ 35$ Canadian for trades up to 1,000 shares on the TSE but \$39 US for trades up to 1,000 shares on the NYSE. Given an exchange rate of about 1.5 Canadian dollars per US dollar, this means that the trade would cost $67 \%$ more on the NYSE than TSE for small trades. Commissions tend to be much more competitive across markets for large traders. Thus, it is expected that any clientele effects will be concentrated among retail investors.

Note 3. Our data is not sufficiently detailed to test directly theories on order splitting as we know neither the identity of the client nor the country from which the order was placed. We do have broker numbers for orders on the TSE but not for the NYSE.

Note 4. As of the end of January 2001, the tick size on the NYSE is one US penny and for stocks priced above $\$ 0.50$, the tick size on the TSE is one Canadian penny. As one Canadian penny is worth approximately 0.65 of a US penny over the period of the study, there is a negligible difference in tick size of one-third of a US penny.

Note 5. In addition to the NYSE upstairs market described above, the National Association of Securities Dealers (NASD) has a third market in which over-the-counter trading of NYSE-listed securities occurs among institutional investors and broker/dealers for their own accounts. Blocks of stock are traded off the floor of the exchange and transactions are recorded on NASDAQ for reporting purposes only. Like the upstairs market on the TSE, the third market of the NASD operates in a non-anonymous way.

Note 6. The only significant characteristics identified by Pulatkonak and Sofianos (1999) that make the Canadian cross-listed securities less than fully fungible are as follows. Canadian stocks bought on the NYSE must clear through the US Depository Trust Company (DTC), must be held in a US dollar account and must pay US dollar dividends. If the dividend is paid in Canadian dollars, an intermediary is needed to convert dividends from Canadian into US dollars in New York. Canadian stocks purchased on the TSE must clear through the Canadian Depository for Securities, must be held in a Canadian dollar account and must receive dividends in Canadian dollars. If a dividend is paid in US dollars, the dividend must be converted to Canadian dollars. Pulatkonak and Sofianos (1999) argue that the requirements of separate clearance and settlement arrangements in the US and Canada encourage a clientele effect whereby Canadians buy cross-listed stocks on the TSE and US investors do so on the NYSE. However, conversations with TSE officials indicated that additional costs associated with clearance and settlement arrangements for a US investor to trade a cross-listed security on the TSE are minimal.

Note 7. Computer software facilitates arbitrage. For example, the BRIDGE trading program allows traders to compare quoted stock prices on Canadian and US exchanges in either currency.

Note 8. The use of the two databases provides comparable information. Jacquillat and Gresse (1998) note problems in comparing volume of French stocks traded on the Paris Bourse to the SEAQ-I which are not present in the NYSE/TSE databases.

Note 9. For the firms reporting financial statements in US dollars, $55.65 \%$ of volume traded was on the TSE and for the firms reporting in Canadian dollars, $83.67 \%$ of the volume traded was on the TSE.

Note 10. There is a high correlation between the explanatory variables in Table V. However, we do not believe that multi-collinearity is a problem for two reasons. First, the correlation is higher between each of these variables and 
the dependent variable than between the dependent variables themselves. We also run the model with March data alone and find that the results are essentially the same.

Note 11. The large number of observations in our regressions means that we must be careful in interpreting the levels of statistical significance using t-statistics. As Zellner (1984) discusses, a large sample size drives the standard error of the coefficient estimates toward zero and produces large t-statistics. Given the considerable risk of type I error, we follow Griffiths and White (1993) and conduct a posterior odds ratio test as an alternate method of determining a critical t-value.

Note 12. No adjustment was made to eliminate book clearing trades before upstairs trades. Smith, Turnbull and White (2001) identify that less than $0.2 \%$ of all upstairs trades on the TSE have trades in the fifteen minutes prior to the trade that were done to clear the limit order book to accommodate an aggressive upstairs order. Keim and Madhavan (1996) discuss how block trades are "shopped" and that this activity may involve a leakage of information. They suggest that a portion of the price impact is experienced in the days prior to the trade, as buyer-initiated (seller-initiated) block trades are preceded by stock price increases (decreases). Thus, on the TSE, it is likely that traders informally "shop" orders without entering them in their order entry systems. For the NYSE, we had no means of distinguishing upstairs from downstairs trades.

Note 13. The higher permanent price impacts on the NYSE could be attributable to information being consistently released in New York before Toronto. To test the hypothesis that the NYSE is a senior exchange to the TSE, we examine which market is more likely to lead the other market. In particular, we test whether, it is more likely that a buyer-initiated block trade on the NYSE is followed by a similar trade on the TSE than a buyer-initiated block trade on the TSE is followed by a similar trade on the NYSE. We measure the percentage of consecutive pairs of trades categorized by different sequences. The sequence of trades is delineated by the exchange where the first and second trade are executed as well as the trades' respective size and initiator. A large (small) trade is greater than (less than or equal to) the number of shares on the opposite sides in the limit order book at the market.

We find that the percentage of cases where the TSE was the first exchange to have a large buy followed by a similar trade type in the NYSE is statistically significantly higher than the percentage of cases where the same type of trade occurs first on the NYSE and then on the TSE. For pairs of large sells, neither exchange shows a statistically significant pattern of leading the other. Thus, we do not attribute the higher permanent price impact on the NYSE to it being a senior exchange in the case of these interlisted securities. 